\title{
Virtual Banking and Financial Inclusion
}

\author{
Tatjana Boshkov \\ Professor at Faculty of Tourism and Business Logistics, \\ University “Goce Delcev”, Stip, Macedonia
}

\begin{abstract}
Financial sector is constantly striving to find new ways to provide financial services to the world's population as the fact that banks play a key role in promoting online businesses. The increase in technology in the financial industry (FinTech) seems to have filled the gap in the inaccessibility of financial services, as facilitating accessibility for all entities to financial tools and services at reasonable costs. Digital Payments, P2P and many others are just an example of the development of FinTech, and while these innovative services have changed the financial world, including many participants in the financial sector, a huge unused portion of the world's population, which does not use a bank, remained non-inclusive.
\end{abstract}

Keywords: digital, banking, financial, inclusion, payments.

DOI: $10.7176 /$ RJFA/10-13-06

Publication date:July $31^{\text {st }} 2019$

\section{Introduction}

The financial sector is constantly striving to find new ways to provide financial services to the world's population. The increase in technology in the financial industry (Fintech) seems to have filled the gap in the inaccessibility of financial services, as facilitating accessibility for all entities to financial tools and services at reasonable costs. Digital Payments, P2P, Robo-Advisers and many others are just an example of the development of Fintech. While these innovative services have changed the financial world, including many participants in the financial sector, a huge unused portion of the world's population, which does not use a bank, remained.

Banks play a key role in promoting online business. Although e-buyers have the possibility of cash income, which appears to be reliable and reliable, there is still a need for e-payment schemes that can be provided only through banks. Banks act as strong and reliable intermediaries in online transactions and provide bold opening in online business. Currently, banks have electronic payment systems such as online banking, electronic funds transfer (NEFT / RTGS), plastic money (credit card and debit card) and mobile banking. These systems enable the payment of on-line transactions, such as online product purchases, mobile additions, hotel reservations, ticket reservations, etc. Taking into account all types of safety measures for the proper operation of these e-services, the need for appropriate infrastructures is an inevitable feature.

With the significant increase in the penetration of mobile phones, linked to the potential public telephone system and the low cost of mobile telephony in India, we can hope that Mobile Banking will be allowed to play a significant role in the pressure for financial inclusion. Providing real-time updates for critical banking transactions is the main benefit of M-banking - for example, soon after a transaction such as cash withdrawal at ATM receives mobile notification via Mobile banking. Although they have a good potential to become a medium for electronic payments and mobile money, M-Banking is not well received by customers around the world (Sudeep, 2011).

\section{Literature review}

Financial inclusion focuses on population which is "unbanked" to get into the formal financial system. In this way, people will have the opportunity to access to financial instruments and financial services - savings, payments as transfers to credit and insurance. This also is a kind of strategy which correct market failures and eliminate nonmarket barriers to access various financial products and services. In total, financial inclusion is without doubt an important topic because it can influence the extent to which financial services and innovations can improve our lives. It is key to provide new opportunities for population in societies by driving forward inclusive global growth. Defining financial inclusion as policy, contributes of finance to economic development and poverty reduction. This underlines the development of policies in finance in developing countries, and gives special place due to the positive impact that finance product and services have on misery index on the countries.

For example, the policies in financial sector take a place through three stages:

1. Fostering state-led industrial and agricultural development through directed credit;

2. Market-led development through liberalization and deregulation;

3. Institution building that aims at balancing market and government failures.

People that are not financially included, are not able to get affordable credit, and are financially at risk due to having no home insurance, struggle to budget and manage money or plan for the unexpected and not know how to make the most of their money (FSD, 2010). For example in the economic literature, Joshi (2011) defines financial inclusion as the process that ensures financial products and services needed by vulnerable groups (low 
income groups at low cost and transparent manner by mainstream Institutional players. According other authors, financial inclusion is defined as a strategy that should reach everyone who wants to use financial services, especial population with low incomes (Gardeva and Rhyne, 2011).

Further, Cheriyan (2011) numbers all type of accessing financial products and services - no frill bank account, financial advisory services, check in account, entrepreneurial credit,micro-credit, savings products, healthcare,remittances \& payment services, business correspondence insurance, mortgage, pension for old age and selfhelp group branchless banking. Gardeva and Rhyne (2011) conclude that financial inclusion as global strategy that utilizes on global growth will be reached in the moment when all people have access to a suite of quality financial services, provided at affordable prices, in a convenient manner for the clients.

\section{Virtual banking: overview}

Technology has really revolutionized the banking operation around the world and has definitely improved the quality of banking services. The literature found that the working environment of bankers has been positively improved after computerization. Users are very satisfied with all high-tech products (Vanaraj, 2011). It was found that the security of the Internet and the privacy of users are the most important future challenges for the banks. Perceived utility, perceived web security has a strong and direct effect on the acceptance of online banking (Aladwani, 2001). The main barriers facing the banking industry in the adoption of e-banking are: security risk, lack of trust, lack of legal and regulatory framework, lack of ICT infrastructure and lack of competition among local and foreign banks (Ayana Gemechu Bulum, 2014). E-banking has stepped up the growth of customer base for banking institutions by improving the accessibility of banking services to the country's larger population (Bichanga Walter Okibo, 2014). The level of customer awareness was identified as a significant issue and there was a significant difference in the level of awareness among consumers of different age groups and professions. Public sector banks continued to play a very prominent role in mobilizing deposits and withdrawing loans even during the privatization period. They contribute about 75 percent of the mobilized deposits and total loans imposed by all commercial banks (K. Rengeswami, DV Gopalapa, 2012). The adoption of new technology by attracting human talent will become very necessary in the future. New technologies such as ATM, internet, mobile banking, data storage with management techniques such as CRM, Human Resource Management (HRM), Information Management System (MIS), Decision Support Systems (DSS) Marketing, etc. will improve the functioning of banking (Satish Tanaji Bhosale, 2012).

Almost $16.5 \%$ of mobile phone subscribers use the Internet through their mobile phones. According to a mobile banking report from Deloitte (Albeh Patel, 2013), 17 million Indians use mobile phones for bank transactions. In 2012-13, Airtel-Axis Bank launched a mobile banking service for financial inclusion and money transfer. According to the operational guidelines for banks by RBI, only those licensed and supervised in India and having a physical presence in India will be allowed to offer mobile banking services (Chugh, 2014). According to the RBI report, there are 82 banks that RBI allows them to provide mobile banking services across India (Spare Bank of India, 2014), compared with 21 banks in 2010.

The cost as an attribute was studied by Sadi and Norind (2011), and found that the estimated cost is also an important factor and has a negative relationship with the intention to accept mobile banking services. These authors suggested that creative promotional and price strategies, including cost reductions, should be implemented to attract customers who are aware of the price. Srivastava and Srivastat (2010) also argue that the resulting financial costs adversely affect the intention to use mobile banking. Researchers have come across many different models that help them identify important factors that influence the attitude and intent of mobile banking users. In the next section, these models are discussed. The mitigating situation is also an important attribute of controlling the behavior of consumers towards the intention to use, therefore, it is necessary to improve the conditions for ease of mobile applications, such as connection speed, secure systems and easy transaction mode (Sadi and Noordin, 2011). In order to meet consumer expectations and increase mobile banking service users, the mobile banking service provider needs to raise awareness of monetary banking services. Banks and mobile service providers need to join together to make a revolution in the field of mobile banking.

\section{Digital inclusive banking}

The majority of the clients had a mobile phone, but only small percent of them use a mobile phone as their way of accessing the banks. This gives them the opening of the bank's marketing section to redirect their attention to this opportunity to attract mobile owners to mobile banking. Today, users using online banking services use their tablets or smart phones to access their banks, but do not use their devices to access mobile banking applications provided by the bank.

People were relatively aware of the mobile bank, but the level of use was very low. Regarding the opinion about the efficiency of mobile banking, its users reveal above the average score. This indicates that the users of mobile banking services provided by banks were accepted by customers. She used the idea to give more attention to the potential of mobile banking. 


\subsection{Digital Finance}

From a practical point of view, digital finance is all those financial services that are delivered through mobile phones, personal computers, the Internet or cards associated with a secure digital payment system. Although there is no standard definition of digital finance, there is a certain consensus that digital finance covers all products, services, technology or infrastructure that enable individuals and companies to access payments, savings and credit facilities online (online) without need from visiting a branch of a bank or without direct mediation with the financial services provider. In Europe, the Internet has emerged as a widely recognized distribution channel for the banking industry, and all traditional banks, as well as new players, discover its performance in comparison with other channels. The goal of financial services that are available through digital platforms is to contribute to poverty reduction and to contribute to the goals of financial inclusion of developing economies.

\subsection{Digital finance and financial inclusion}

The theoretical basis for the relationship between digital finance and financial inclusion is the thesis that much of the excluded population owns a mobile phone and that the provision of financial services through mobile phones and related devices can improve access to finance for the excluded population. If the excluded population has a mobile phone and an affordable internet connection, it is often envisaged that the greater supply of digital finance will have positive effects on financial inclusion, while all other things are equal, which implies a positive correlation between the use of digital finance and access to formal financial services.

New time of technology show that low-income countries invest in more modern and less-intensive wireless telecommunications infrastructure. This new time of technology revolution brings more intensive development of financial infrastructure. As drivers of financial services are Fintech companies and mobile operators that joined to the banks and finance institutions. Thus provider are more motivated and invest in a network for delivering financial services and reaching potential customers via their mobiles during the fact that Mobile devices are becoming digital wallets, virtual bank accounts as point of sale.

The adoption of digital technologies increase the financial inclusion and lowers the cost of initiating and maintaining financial relationships for institutions and consumers. Digitisation helps reduce the time of waiting and paperwork. This helps to financial institutions in reaching and transact with customers. This step is very important for banks serving low-income customers who transact more often and manage lower amounts of money. The benefit for the customer is spending less time and money going to a branch or waiting. Costs are reduced for all entities. Excluded segments of the population have new opportunities to access better quality financial services.

Companies across the world create new financial products and services delivered via digital platforms, and low- and middle-income customers are testing their functionality and engaging with the broader financial system. Policymakers and regulators are determining the extent to which they need to set the terms, incentivize and mediate these relationships.

Figure 1. Regional average scores on infrastructure domain

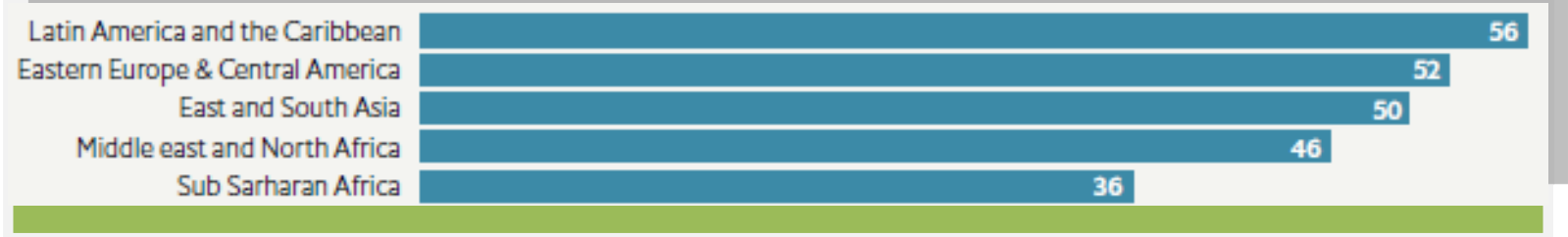

Source:EIU, 2018.

\section{The role of the Government in financial inclusion}

Governments can promote digital financial inclusion by expanding payment platforms for government transactions. Strong person-to-government (P2G) and business-to-government (B2G) payment platforms exist in a number of countries, conditions can be improved. The significant size of the public sector in most countries and the pervasiveness of making payments to or receiving payments from governments mean that when authorities introduce digital payment options they can influence the behaviour of a mass of individuals, incentivising them to switch to digital payments. For example, in Kenya, the government has taken advantage of wide acceptance of mobile money to extend its services via an e-government platform. Mobile money represents more than $90 \%$ of payments via the platform and more than $85 \%$ of payments for parking fees, single business permits and licences. Services such as drivers' licences can be paid for only via the platform. Government actions can spur the development of digital payments infrastructure through the platforms that increase the technical capacity and options available to rest of the market.Also, the government can reap sizeable gains, including reducing administrative costs, increasing security and broadening tax bases. Jordan, Paraguay and South Africa combine initiatives to digitise government-to-person $(\mathrm{G} 2 \mathrm{P})$ payments, such as pensions, with $\mathrm{P} 2 \mathrm{G}$ and $\mathrm{B} 2 \mathrm{G}$ payment platforms that allow all parties to pay online taxes and other charges. 


\section{Effects and gains of digital finance on financial inclusion}

The positive effects of digital finance on financial inclusion are different. Difficult digital finance, when applied in the lives of low-income and poor people, can improve their access to basic services, leading to greater financial inclusion in rural areas. Greater digital financial services targeting rural and poor communities can improve access to finance for banking customers in rural and poor communities who can not easily access banks located in the formal sector due to poor transport networks and long hours of waiting in bank halls and to reduce the presence of bank customers in the banks' branches, and also to cut costs because the bank will have more efficient maintenance of few branches, and the lower costs would have t positive effects on the profitability of banks and financial inclusion in rural and poor communities.

Easy to use, digital finance can provide a more convenient platform for individuals to carry out basic financial transactions, including electricity, water, money and family transfers, and so on. If digital finance platforms are easy to use, digital financial service users can help and inform and persuade their peers in the formal and informal (rural) sector to take advantage of digital financial services, leading to a larger number of people who use digital finance, which in turn will lead to greater financial inclusion. The only warning here is that although there may be a positive link between the easy use of digital finance and financial inclusion, it is necessary to emphasize that the implied positive relationship is stronger for users of high and middle income of digital finance, while the relations can be non-linear or negative for low-income and poor users of digital finance, as users of digital finance in poor communities, despite persuasion, may refuse to use digital services funded by the superstitious and religious beliefs they have in terms of technological advancements and innovations or inaccessible fees charged by digital financial service providers or financial illiteracy, and other reasons.

In addition to the numerous benefits deriving from digital finance, there are also negative effects of these, which are primarily derived from the profit motives of the providers themselves.

Digital financial services providers are profitable corporations that use digital finance to increase their profitability or increase the lucrative capabilities of businesses associated with providers of digital finance such as banks, and other financial and non-financial institutions. Corporate digital financial service providers can discriminately use more aggressive marketing tactics to persuade high and middle income customers to use a new or existing digital financial platform or infrastructure, and use less aggressive marketing tactics to persuade lowincome and poor clients to use new or existing digital platforms or infrastructure if they believe that the latter can not afford the associated fees, which will lead to a reduction in the financial involvement for poor and low-income clients, because the net monetary payment to providers of digital finance is greater with high and middle income customers than low-income and poor clients. Distribution in the provision of digital finance may also be geographically, because digital finance providers, based on their own internal risk assessment, which may change from time to time, may choose to withdraw or to discontinuing the provision of specific digital funding services to high-risk rural areas or communities that do not have an associated infrastructure to maintain specific digital finance services, leading to a reduction in financial inclusion. Some accompanying infrastructures required for the efficient operation of the DFS may include mobile phones that have modern (and up-to-date) operating software systems and applications that support digital finance services. Educational prejudices can be introduced in the provision of digital financial services. If the net monetary value of providing digital finance to poor communities is very low, digital finance providers, on the basis of their profitability assessment, may choose to focus less on the delivery of digital finance to poor and uneducated communities that do not have a basic financial literacy to use and understand digital finance.

\section{Conclusion}

The rapid global information infrastructure (including information technology and computer networks, such as the Internet and telecommunications systems) enables the development of electronic commerce on a global scale. Almost the universal connection that the Internet offers makes it an invaluable business asset. These developments have created a new kind of economy, which we can call a "digital economy".

This fast-growing economy brings rapid changes to technology, increases the intensity of knowledge in all areas of the business and creates virtual supply chains, new forms of business and delivery channels such as ebanking. As a direct consequence of the emergence of the "digital economy", the balance of power seems to change to customers. The change of the economy from a traditional way to the recently requested form requires extensive technology support and effort, better planning and efficiency in implementation.

The banking business phase drastically changes, especially in their transactions that are from conventional to smart. To support the operation of online business, all banks design different products. One of the medium through which customers can be accessed is via mobile. Because the mobile device appears in its importance in a wide range of people around the world, it will be better to take this opportunity and use it as a medium in banking and online business. There is still a huge gap that needs to be filled by banks to use mobile as one of the ways to gain access to the Internet. 


\section{Reference}

Aladwani, M.A. (2001). Online banking: a field study of drivers, development challenges, and expectations, International Journal of Information Management, pp. 213-225.

Alfandika, N. and Bendick, M. (2015). A SWOT analysis of mobile electronic banking: The Zimbabwe case, International Journal of Electronic Finance, 8, No.2/3/4, pp. 218-238.

Alpesh, P. (2013). M-Banking and M-Payments: The Next Frontier, Delhi: Deloitte.

Bichanga, W.O. and Ali, Y.W. (2014). Effects of E-Banking on Growth of Customer Base in Kenyan Banks, International Journal of Research in Management \& Business Studies, IJRMBS 2014, 1. pp. 78-85.

Boskov, Tatjana (2016) Growing the Global Economy through SMEs International Aspirations. LAP LAMBERT Academic Publishing, Germany. ISBN 978-3-659-95344-6

Chaia, Alberto, and others. 2009. "Half the World Is Unbanked." Framing Note. New York: Financial Access Initiative (October).

Chatain, Pierre Laurent, and others. 2008. "Integrity in Mobile Phone Financial Services." Working Paper 146. Washington: World Bank.

Cheriyan G (2011). Financial Inclusion. The IIPM Think Tank

Demirguç-Kunt, Asli and Ross Levine, 2008. "Finance, Financial Sector Policies and Long-Run Growth". Policy Research Working Paper No. 4469, World Bank

Financial Sector Deepening Trust. 2010. FinAccess National Survey 2009: Dynamics of Kenya's Changing Financial Landscape (www.fsdkenya.org/finaccess/documents/09-06-10_FinAccess_FA10_Report.pdf).

Gardeva, A., \& Rhyne, E. (2011). Opportunities and obstacles to financial inclusion: Survey report. Washington, DC: Accion, Center for Financial Inclusion. Retrieved from https://centerforfinancialinclusionblog.files.wordpress.com/2011/12/opportunities-and-obstaclestofinancial-inclusion_110708_final.pdf

Joshi DP (2011). Financial Inclusion and Financial Literacy BI OECD SEMINAR - Roundtable on the updates on Financial education and Inclusion programmes in India.

Subbarao, P.S. (2007). Changing Paradigm in Indian Banking, Gyan management, 2, pp. 151-160.

Sudesh, K. and Bimal, A. (2014). Electronic Banking: An Emerging Way of Customer Services, Research Journal of Management Sciences, 3 (4), April 2014, pp. 1-4

Sultan, S. and Sahila, C. (2011). E-Banking Scenario And Its Impact On Customers' Satisfaction In India, International Journal Of Research In Commerce \& Management, 2 (4), pp. 29-34

Townsend, Robert M., and Kenichi Ueda. 2006. "Financial Deepening, Inequality and Growth: A Model-Based Quantitative Evaluation." Review of Economic Studies, 73 (1): 251-93.

Uppal, R.K. and Kaur, R. (2007). Indian Banking: Moving Towards IT, Journal of Commerce and Trade, 2 (1), pp. 26-32.

Uppal, R.K. and Kumari, R. (2009), Indian Banking Vision - 2020, Sarup Book publishers pvt. Ltd, New Delhi.

Vanaraj, V. (2011). Impact of Information Technology on Indian Commercial banks - A comparative study of Kerala and Tamil Nadu, PhD Thesis (IMK - Kerala University).

Vinayagamoorthy, A. and Sankar, C. (2012). Mobile Banking - An Overview, Advances In Management, 5 (10), pp. 24-29.

World Bank. 2007. Finance for All? Policies and Pitfalls in Expanding Access. Policy Research Report. Washington D.C.: World Bank. 